\title{
XIX. On the want of uniformity in the action of copper-zinc alloys on nitric acid
}

\section{Dr. J.H. Gladstone F.R.S.}

To cite this article: Dr. J.H. Gladstone F.R.S. (1900) XIX. On the want of uniformity in the action of copper-zinc alloys on nitric acid , Philosophical Magazine Series 5, 50:303, 231-237, DOI: 10.1080/14786440009463907

To link to this article: http://dx.doi.org/10.1080/14786440009463907

册 Published online: 21 Apr 2009.

Submit your article to this journal $₫$

Џ Article views: 3

Q View related articles $\square$

Citing articles: 1 View citing articles $\square$ 
On the Action of Copper-Zine Alloys on Nitric Acid.

tried; for I find that in some cases the branches only approach considerably towards each other, while in other cases they merely cross each other, but never entirely reverse their relative positions as expected.

It seems, then, that I was able to show by the above experiments, defective and incomplete as they were:-

(a) That in soft iron of certain kinds there exists the phenomenon of thermo-electric hysteresis with respect to twist (at least when combined with longitudinal tension);

(b) That, other things being equal, the hysteresis is reversed at a certain twist ;

(c) And that mechanical agitation has its own effects, which are reversed as the hysteresis is reversed.

XIX. On the Want of Uniformity in the Action of CopperZine Alloys on Nitric Acid. By Dr. J. H. GLadstone, F.R.S.*

M

$\mathrm{UCH}$ attention is being directed at the present time to methods by which it may be possible to determine the heat evolved in the formation of alloys. Among these methods is that of the dissolution of filings of the alloys of copper and zinc in nitric acid, as compared with the dissolution of mixtures of the two metals in the same proportion. This method has been objected to by more than one chemist on the ground that there is no assurance that the same substances, and in the same relative proportions, are produced in each case. As my name appears on the British Association Committee which has adopted this method, I have felt myself under an obligation to make some direct experiments on the point.

In the Report of this Committee, "On the Heat of Combination of Metals in the Formation of Alloys," read at the Dover Meeting of the British Association (Report, 1899, p. 246) a table is given containing details of a long series of observations, which show the heat developed during the action of nitric acid on copper and zine in various proportions, both when the metals are mixed together and when they are in combination as alloys. The difference of heat between the solutions compared has been regarded as a measure of the heat evolved by the combination of the metals in forming the alloy.

The alloys experimented upon by Dr. Galt are twenty-two in number. The results are set out in a table, and plotted in

* Communicated by the Physical Society : read May 11, 1900.

\section{R 2}




\section{Dr. J. H. Gladstone on the Want of Uniformity in}

a diagram. This is reproduced, as far as the little crosses are concerned, on a larger scale in the accompanying diagram.

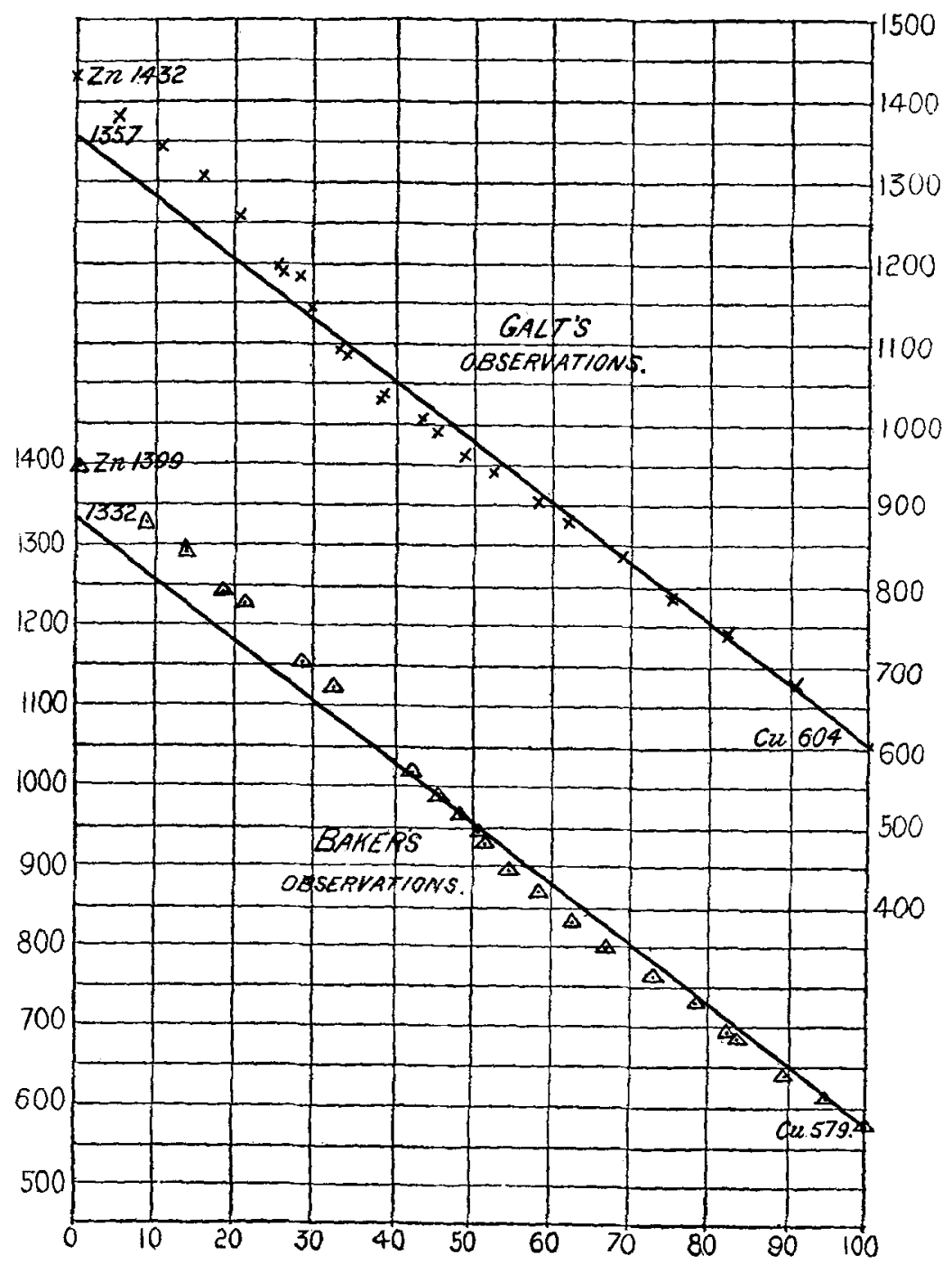

The crossestrepresent the absolute amount of heat evolved in dissolving one gramme of metal or alloy expressed in calories. They show at first a pretty regular decrease in the calories from the 1432 evolved by pure zine towards the 604 evolved by pure copper. But after the alloy containing 20 per cent. 
of copper, a more rapid and irregular decrease takes place till we arrive at that containing 38 per cent. of copper. From this point, or rather from copper 38.38 per cent., there is a gradual and fairly regular descent to the amount of heat evolved by pure copper.

The somewhat similar series of experiments conducted by Mr. Baker (Proc. Chem. Soc., Sept. 1899) is exhibited in the lower part of the same diagram, the resulting calories being plotted in the same way from 1399 down to 579 . There is a fairly close resemblance between the two series, except that in the latter the most rapid decrease of heat does not take place till at about 54 per cent. of copper.

Through the kindness of Lord Kelvin I obtained three specimens of the alloys employed in Dr. Galt's experiments; the first containing 20.5 per cent. of copper and 79.5 per cent. of zinc, the second 38.38 per cent. of copper and 61.62 per cent. of zinc, and the third $49 \cdot 1$ per cent. of copper and $50 \cdot 9$ per cent. of zinc. The first and second specimens are not fir from those which show the greatest divergence in opposite directions in the amount of heat evolved ; in the third the two metals are very nearly in atomic proportions. In dissolving these in nitric acid I followed essentially the process employed by Dr. Galt, with the precautions mentioned by him.

As is well known, the reaction between nitric acid and these metals or alloys is very complicated, producing nitric and nitrous oxides and nitrogen, evolved as gases but which may be partially or wholly absorbed; while the liquid is found to contain, in addition to the undecomposed acid, nitrous acid, and nitrates or nitrites of the metals, and in some cases ammonium salts.

The gases have already been the subject of examination by several experimenters. Messrs. Acworth and Armstrong (Journ. Chem. Soc. 1877, p. 54) showed that in the case of copper in nitric acid the gas obtained is almost entirely nitric oxide, while in the case of zinc it is mainly a mixture of nitric and nitrous oxides in very nearly equal proportions. In an experiment with brass they obtained practically the same result as with copper alone. As far then as the gases are concerned, the chemical action of copper and of zinc on nitric acid is not the same ; and the insignificant quantity of the nitrous oxide when brass is dissolved suggests an essential difference in the reaction between the alloy and the mixed metals.

It did not seem necessary to repeat the experiments of Armstrong, especially as the permanent gases evolved in Dr. Galt's experiments were small in quantity, at any rate in the case of the yellow alloy. My attention has therefore been 


\section{Dr. J. H. Gladstone on the Want of Uniformity in}

mainly confined to determining the substances remaining in solution, i.e. the nitrous acid and the ammonia.

The following Table gives the results; they represent in each case the amount produced by one gramme of metal, mixture, or alloy, as the case may be. Usually 0.4 gramme was dissolved in nitric acid, and the resulting solution was divided into two equal parts for determining the nitrous acid and ammonia respectively. The figures given in the Table are the mean of several observations, which were generally fairly accordant, calculated for one gramme. To these are added the results of two specimens of commercial brass of higher percentage of copper.

Table $\mathrm{I}$.

\begin{tabular}{|c|c|c|}
\hline \multicolumn{3}{|c|}{ Products of Reaction, calculated for 1 gramme. } \\
\hline Substance. & Nitrous acid.! & Ammonir. \\
\hline Zine $\ldots$ & 0.057 & $0 \cdot 0164$ \\
\hline Cu 205 per cent., $Z n$ 79.5 per cent.: $\left\{\begin{array}{l}\text { mixture... } \\
\text { alloy ...... }\end{array}\right.$ & $\begin{array}{l}0 \cdot 165 \\
0 \cdot 185\end{array}$ & $\begin{array}{l}0.0275 \\
0.0098\end{array}$ \\
\hline Cu 38.38 per cent., $Z_{n} 61.62$ per cent.: $\left\{\begin{array}{l}\text { mixture... } \\
\text { alloy ...... }\end{array}\right.$ & $\begin{array}{l}0.270 \\
0.552\end{array}$ & $\begin{array}{c}00192 \\
\text { trace }\end{array}$ \\
\hline Cn $49 \cdot 1$ per cent., $Z_{n} 50 \cdot 9$ per cent. : $\left\{\begin{array}{l}\text { mixture... } \\
\text { alloy } \ldots . . .\end{array}\right.$ & $\begin{array}{l}0 \cdot 431 \\
0.568\end{array}$ & $\begin{array}{c}00130 \\
\text { trace }\end{array}$ \\
\hline Cu 65.8 per cent., $Z_{n} 335$ per cent.: alloy .... & 0568 & trace \\
\hline $\mathrm{Cu} 73.5$ per cent., $\mathrm{Zn} 26.5$ per cent.: alloy ...... & $0 \cdot 600$ & trace \\
\hline Copper ............. & $0 \cdot 605$ & trace \\
\hline
\end{tabular}

If the copper and zinc in the proportions above mentioned had been dissolved separately in acid, and their solutions then mixed together, nitrous acid and ammonia might have been expected to be in the following proportion :-

TABLE II.

\begin{tabular}{|c|c|c|}
\hline Mixture of Solutions. & Nitrous acid. & Anmonia. \\
\hline Cu 20.5 per cent., Zn $79 \cdot \tilde{s}$ per cent. & $0 \cdot 169$ & $0 \cdot 0130$ \\
\hline Ou 33.38 per cent., $Z$ n $61 \cdot 62$ per cent. ... & $0 \cdot 267$ & 00101 \\
\hline Cu $49 \cdot 1$ per cent., $\mathrm{Zn} 509$ per cent. ...... & 0.326 & $0 \cdot 0083$ \\
\hline
\end{tabular}


Two results stand out prominently from the above figures.

1 . The chemical action of the alloys is very different from the chemical action of the corresponding mixtures of filings. It will be seen by a glance at Table $I$. that the alloys give much more nitrous acid and very much less ammonia than the corresponding mixtures. In fact, two of these alloys give practically no ammonia.

2. On comparing the figures for the mixtures of solutions in Table II. with the solutions of mixed metals in Table I., it will be seen that there is a notable difference both in regard to the nitrous acid and to the ammonia. This might be anticipated from the fact that, when the copper and zinc filings are mixed together, they form what has been described under the name of the "copper-rinc couple." The two metals in juxtaposition and touching at a multitude of points while surrounded by acid set up a more vigoruus action, with different chemical results and no doubt a different evolution of heat*. It is probably this action which causes Dr. Galt's numbers for heat of mixtures to lie generally below the theoretical straight line joining zinc and copper in the diagram accompanying the report of the Committee.

The chemical objection therefore is well founded. It is a very serious one; but is it necessarily fatal?

Would it not be possible to take some particular alloy, determine the products of its action on nitric acid, and their relative proportions, and then determine the number of calories which would be produced theoretically in the reaction? If they ngree closely with the number of calories found by Dr. Galt and Mr. Baker, there is no room for supposing that the amount of heat evolved in making the alloy is to be determined by this method. If, however, the two calculations differ, there is a residual phenomenon to be explained.

But here we encounter two difficulties.

1. Though we may know the ultimate composition of all the specimens of copper-zinc alloys experimented upon, probably not one of them is a truly definite compound. Each of them may consist of two or more alloys with some uncombined zinc or copper, as the case may be. A microscopical examination is generally sufficient to show that each is more or less beterogeneous in its character. Sir W. RobertsAusten's table of the freezing-points of alloys of copper and zinc also indicates the mixed nature of almost every specimen

* See Journal Chem. Soc., April 1878, where the experiments of Prof. Thorpe and of Gladstone and Tribe on the production of nitrite and ammonia by means of the copper-zinc couple are described. 
examined. The alloy $\mathrm{Cu} 38.38$ per cent. appears, however; to be pretty uniform.

2. Supposing, however, that we had the true constitution of the specimen and the exact products of the chemical aetion both in solution and as gases, there would still remain an uncertainty about the number of calculated calories. The original determinations of Thomsen and the recent ones published by Berthelot are very discrepant ; and the various corrections to be made, especially in regard to the gases, are too uncertain to admit of any trustworthy comparison within the nurrow numerical limits with which we have to deal.

There is, however, another method of comparison which appears to be more promising. Although Thomsen and Berthelot differ as to the calories produced by any particular reaction, there is one point on which they practically agree : that is, the excess of calories in a zine reaction over those in the corresponding copper reaction. Thomsen makes it for one gramme 750 calories, Berthelot 756 calories, which is a practical agreement (say 753 calories). Starting from 604 calories, the value, according to Galt, when pure copper is dissolved in nitric acid of sp. gr. 1:360, we should bave 1357 calories when pure zine is dissolved, provided the chemical action were the same in each case; and all the calorimetrical results from the different specimens of alloy would theoretically lie, not upon the line drawn in Dr. Galt's diagram, but upon the straight line drawn between 604 and 1357. On referring to the diagram, we see that the little crosses fairly coincide with this line from pure copper to about the $\mathrm{Cu} 70$ alloy, but beyond that there is less beat produced than the mean indicated by the straight line, the maximum deviation being at about $\mathrm{Cu} 37$. Beyond that point the heat gradually augments, exceeding the mean at about Cu 30, with a somewhat irregular progress to 1432 calories, the amount experimentally obtained by Galt from pure zinc, -an excess of as much as 75 calories above the theoretical. The diagram of Baker's experiments shows the same general result, with the difference previously referred to.

Reference to Table I. will show that the products of decomposition of the nitric acid between pure copper and the $\mathrm{Cu} 38 \cdot 38$ per cent. alloy give nearly the same amount of nitrous acid in each case (representing about 80 per cent. of the possible amount), and practically no ammonia. The remaining 20 per cent., or thereabouts, consists mainly of nitric oxide. As the products in each of the five cases seem to be the same, and nearly in the same proportions, we should expect that the amounts of heat evolved would form a pretty 
regular progression between copper and the above alloy, following closely the theoretical line. We see a fair approximation to this in the diagram, but there is a gradual divergence from the line, indicating a deficit of heat. The specimen containing 38.38 per cent. of copper, which is not fiu from the predominant alloy $\mathrm{CuZn}_{2}$, shows a loss of 32 calories. Baker's experiments show almost exactly the same amount of loss of heat, though at a somewhat different place in the series.

The only way in which, as far as I can see, this residual deficit can be explained on chemical grounds, is by supposing that the action of this alloy upon nitric acid produces a larger amount of nitric oxide than in the case of pure copper. Table I. gives some indication that this may be the case, because the amount of nitrous acid produced is rather smaller in the alloys than with the metal itself, indicating that there must be more of some other product, presumably nitric oxide. But, allowing full force to this argument, it cannot account for as much as 10 calories of the deficit. There is in any case a residual deficit as yet unaccounted for on ehemical grounds, and which may be regarded as the amount of heat evolved in the formation of the alloy.

The action of zinc, or of the alloys rich in zinc, upon nitric acid is very different. There is less nitrous acid formed, while ammonia and nitrous oxide are produced in considerable quantities. The substitution of ammonia for nitrous acid will not make much thermal difference; but as the calories obtained by the formation of nitrous oxide are at least 175 more than with nitric oxide, and 83 more than with nitrous acid, there does not seem any difficulty in accounting for the excess shown between the observed and calculated values for pure zinc, or for the alloys containing more than 70 per cent. of this metal.

The work both of Dr. Galt and Mr. Baker has evidently been carried out with the greatest care; but, considering the uncertainty of the thermo-chemical data and the great physical interest attaching to the research, it would seem highly desirable that further experiments on the copper-zine alloys should be made with solvents which give a chemical action far more simple than that produced by nitric acid.

In concluding, I desire to acknowledge the great assistance Mr. Hibbert has rendered me in this inquiry. 